Original Contribution

\title{
THE DIGITAL NATIVES IN THE NEW AGE
}

\author{
V. Georgieva* \\ Faculty of Education, Trakia University, Stara Zagora, Bulgaria
}

\begin{abstract}
The article refers to the New Age, to the widespread use of social media, to the digital natives and their features, to social media's meaning, types, classifications and learning opportunities, social media's psychology, possible risks, digital legacy. In the end the article shows the need of serious research on Bulgarian conditions.
\end{abstract}

Key words: new media, social media, social networks, facebook, net generation, social media's psychology, digital legacy

\section{INTRODUCTION}

Contemporary New Age embodies society's development, the progress in improving the technology and the intention to create a cosmopolitan language and civilization, based on the global view to the world where there are no limits for human potential and possibilities. Social media is a temporal problem in the new digital age that exceeds the prerogatives of the technology and impact on the personality and its socialization directly. These new media are part from the daily life of our contemporary and characterize his daily culture. Trough social media the social person purchases goods and services actively, compares prices saving precious time and energy, follows fashion trends, organizes holidays and vacations, does banking transactions, has fun, forms and defends views, likes or criticizes people, events and phenomena, searches for and finds the needed information, studies, looks for a job, declares himself, his marital status, shows his possessions, the food he eats, displays the material things he wants to own, appeals his spiritual yearnings, even he flirts and creates a family, checks in on the location

he is at the moment or the places he had been, enjoys and comments arts, music, movies, photography, pictures, chooses a doctor,

*Correspondence to: Violeta Georgieva, PhD student in the Faculty of Education at Trakia University, Stara Zagora shares his social progress and achievements, his moment mood, converses...every day. In 2009 two-thirds of the global internet population participate social networks and this is the most performed online activity, even before checking the personal email address (1). It is known that it takes more than 412, 3 years to be watched all the videos in YouTube and this is not surprising because every minute the users upload video materials totally 13 hours long. In Wikipedia there are 13 million articles available, the photos archived on Flickr by mid-2009 are 3.6 millionroughly one photo of every two people on the planet. After only two years the archived photos increase double. Currently users upload 3.5 million photos every day. In another social network (Twitter) the activity is very high alsousers write more than 3 million tweets daily. The most popular in Bulgaria social network Facebook in October 2012 has more than 1 billion users. In the virtual world Second Life the users called inhabitants, are million and a half (2). $83 \%$ of people between 18 and 29 years of age, $70 \%$ people between 30 and 49 years of age, $51 \%$ of the people aged over 50 are active users of social media. $98 \%$ of Europeans know social media and $73 \%$ are members of one social network at least (3). We can add many more such findings but it is a clear and unconditional fact that the society has changed significantly. Galin Tsokov rightly points out that communication between people is virtualized and it is already in its New Age (5). Already social 
media present in the biography as a document. In the latest form CV European format to the section "Personal information" social network is at the fourth place right after the name, address and phone. Social media is not a whim, but a real phenomenon. There is no way to hide or deny the fact that social media is a present and a future, that social media carry many risks and many opportunities for the society, organizations and individuals. These are enough reasons social media's significance and spread to be discussed in the annual international event "Social Media Week", during which hundreds of thousands of people in over 10 countries, more than 9 languages simultaneously discuss the social, educational, cultural, psychological and economic impact of social media. The event is a real time demonstration of some of the best ideas, strategies and insights from the people who shape the future (5).

\section{Digital natives}

All children born after 1991 compose so called Net generation or Z generation, or Google generation. They are the digital natives. The latter term is defined in the Oxford English Dictionary as "a person born or brought up during the age of digital technology and so familiar with computers and the Internet from an early age" (6). These young people are in constant contact with the information and communication technologies, they take them as normal granted and could not live without them. The same young people based their views, judgments, beliefs, perceptions, worldviews, values and moral orientation on the social environment, its factors and the society they grow up, but on the social media too. The digital natives students own very high technical skills, they are relaying on the searches in Internet, prefer and choose to be informed by Internet rather than paper books and textbooks, they are extremely interested in modern and new technology and multimedia tools, they generate their own contents, they prefer to study by discovery learning and the methods of experiment and error, they are able to do several activities at the same time-multitasking, they are emotionally open and they love to share all the things that excite them in the social network, they require a permanent feedback, they prefer to use the keyboard than to write by hand, and many more characteristics can be added (7). For the growing up digital natives the whole world is collected in one small box, which they carry in their pockets. In that box they have all their contacts, no limited access information, contact with people like them around the globe in real time-all these in one click distance. So they grow up with very different consciousness than that of their parents and previous generations. Media pedagogy has explored the impact of mass media (radio, TV, Internet) on children and students carefully. Therefore is not it quite natural and expected to turn its eyes to the phenomenon social media? The social media's importance and impact are felt, but still not outlined and clarified sufficiently and clearly among educators, stakeholders, teachers, students and parents. At the same time we have to mention the phenomenon's nature, boundaries and contents.

\section{Social media}

Social media is a communication which is supported by online tools such as YouTube, Technoradi, FeedBurner, Wikipedia, LinkedIn, Facebook, Digg, MySpace, Twitter, Flickr and others (8). Andreas Kalpan and Michael Naenlein define social media as a group of Internet-based applications that build on the ideological and technological foundations of Web 2.0 and that allow the creation and exchange of usergenerated content (9). In recent years, there are many definitions of social media, but they all allow us to bring out their most important characteristics, which are compulsory components that categorize these media as social media. The components are technology, real people and interaction. The last two components have a living nature and they are the real differences and features that distinguish social media than traditional media. Based on the implementation of a set of theories in the field of media research, Kaplan and Haenlein (10) establish classification contained six different types of social media: collaborative projects-for example Wikipedia; blogs and microblogs-such as Twitter; content communities-as YouTube, DailyMotion; social networking sites such as Facebook; virtual game-worlds for example, World of Warcraft; virtual social worlds as Second Life. The boundaries between different types of social media are not identified very clearly. For example, Zhan Shi, Huaxia Rui and Andrew Whinston argue if Twitter is a social network, or should be taken as a broadcaster with elements of social network (11).

\section{Social networks}

In the article are mentioned the most popular social networks briefly. On Internet social networks' history begins with online communities like Theglobe.com (1995), Geocities (1994) and Tripod.com (1995). 
MySpace- platform is founded in 2003 by Tom Anderson and Chris DeWolfe. By June 2012 the platform has 25 million U.S. users (12).

VKontakte is a social network which is available in several languages and is the most popular among Russian-speaking users around the world, especially in Russia, Ukraine, Azerbaijan, Kazakhstan, Moldova, Belarus and Israel. By the end of 2012 the platform has 228 million users (13).

LinkedIn is a professional social network for specialist people belonging to certain professional fields. Since June 2013 there are more than 259 million users in more than 200 countries. The site is available in 20 languages.

Odnoklassniki is a platform for classmates and old friends. The site is developed by Albert Popkov in 2006. The site has 148 million registered users. People under the age of 7 cannot have a profile in this platform (14).

Google+ is a social network created, owned and operated by Google Inc. Sources such as The New York Times announced the service as the greatest experiment of Google to compete with the social network Facebook (15).

Twitter was founded in 2006 by Jack Dorsey, Evan Williams, Biz Stone and Noah Glass. The users of this social network send and read status messages known as "tweets". Tweets are digital text messages up to 140 symbols. Twitter is described as "the SMS of the Internet" (16).

Instagram is an online social network for sharing photos and video from smartphones. The users take photos and video and after that share them in the social networks which they use such as Facebook, Twitter, Tumblr, Flickr and others.

Foursquare is the online social network for mobile devices. Users check in to certain locations. Identification of the location is based on the GPS hardware browser. Each entry in the system gives the user points and sometimes badges. The user with the most check-ins on a location becomes the "mayor" of that location, so users of this platform aspire to become mayors in more places. Facebook is definitely the most popular social network in Europe. The name Facebook comes from the colloquial name of the book given to students in American universities at the beginning of the school year in order to get know each other, and administration to meet them (17). The platform is based at Harvard
University in 2004 by Mark Zuckerberg and his roommates and colleagues Eduardo Saverin, Andrew McCollum, Dustin Moskovitz and Chris Hughes. Initially the membership was only for Harvard students, but then it becomes possible for students from other universities too. Now anyone who claims to have over 13 years of age can register. The users can join groups in which they are interested in. These groups can be organized by workplace, school, and others. Users can categorize their friends into different "lists" such as "Close Friends", "Colleagues", "Family" and others. By September 2012 Facebook has more than 1 billion active users (18). According to a research (19) in 2011, there are 7.5 million children under age 13 with accounts on that social network.

The digital natives spend most of their Internet time in social networks, but alongside, they are not deprived of the use of online video sharing sites. The most popular such site is YouTubecreated in 2005 by Steve Chen, Chad Hurley and Jawed Karim. This is a site for sharing videos created by users, including videos, movies, recordings, television shows, various artists' music. In YouTube can be found a large amount and diverse in character education video recordings of lessons, lectures and materials which illustrate the main and most important topics and lessons studied at school, various demonstrations and practical exercises, beautifully illustrated scientific and popular scientific facts and more. This makes the platform not only entertaining site, but emphasized educational, didactic, methodological and aesthetic source of knowledge. Another similar site is Vbox7, although it should be noted that it is the most popular site for video sharing particularly in Bulgaria. The site was launched in 2006 when visited by only 23 people. Two years later there are thousands of registered users.

This, even a cursory review of the occurrence and the extent of social media, illustrates sufficiently unambiguous presence, significance and trends and the impact of these media on the lifestyle of the individual, different groups of people and modern society in general. The problem of social media has been studied in depth by marketing.

\section{Social media's educational opportunities}

Social media contain some educational opportunities, but it must be highlighted that they can not replace the role of the school and the role of the teacher in the learning process. These roles 
are and will be the most important roles always because there are no social media which have the possibilities to replace the teacher's emotional, professional and personal skills, his proactivity and alive interaction between teacher and student. Meanwhile, the school education system is facing a major challenge-to provide adequate education for pupils whose way of thinking, behavior, preferences, expectations and learning style are totally different as those of teachers and the students generations before them (20). It is necessary to respond adequately to current students, to be found adequate learning for them so that to be kept the tradition and the classic and at the same time to reflect the style of learning and thinking of these students. In this way, teachers will continue to be the most knowledgeable figure for the students and will prevent the gap that social media could form between teachers and students. Nowadays this problem is one of the most topical problems whose solution is sought in Europe and the USA. Educators in Western Europe are increasingly paying attention to the increased popularity and influence of social networks. It is clear that social media are informational and relational portals that are unobservable (for now) paths to knowledge. In September 2013 in Sweden, Annika Lantz-Andersson, Sylvi Vigmo and Rhonwen Bowen publish research related to how students interact in social networks and how they would be useful in the practice of teaching and learning. The research covers 60 students aged between 13 and 16 years in California, Finland, Sweden and Taiwan. The result shows Facebook as an opportunity for learning a foreign language. Students combine their subject in a foreign language with daily interaction with other children in the target language in social networks (21). In 2013 Ioana Boghian publishes a book which answers the question: Is it possible Facebook to be seen and used as an effective and efficient learning tool? If so, how? (22).

There are questions that need urgent answers: Which social media would help to facilitate understanding of the material at school? Could some of them be used as effective learning methods? Would it be easier to achieve individual approach to each student, through social networks? Could be easier to exchange professional experience (internationally) between teachers? Does social media offer opportunities for self-learning, creativity, innovations? Could they form a strong students' motivation for learning? Could they help strengthen communication between teacher and student, between teacher and parent? Is it possible the communication in social media to be kind of pedagogical communication? Could social media show (because they are so popular) models and examples of behavior? Could they be a part of the individuality of the modern teacher? Could they lead to the emergence and development teacher's new roles? Could they be a part of the conceptualization of long life learning? Moreover, the didactic possibilities of social media, although in different ways and with different specifics are in accordance with the didactic principles.

\section{Social media's psychology}

For several years, the psychology deals the issue of social media too. That led to one of the youngest psychology's section called "Social media's psychology". This field is still in its early days, but interest in it is growing very fast. Social media's psychology deals with the description and explanation of human behavior in the context of social media. Also it studies people's behavior, its formation and structure, interpersonal relationships and behaviors. Also that young field seeks to answer the questions: Why do people use social media? How did thy use it? What are their goals? What are these people looking for? And what's next? All these questions eagerly await answers, but there is no way these answers to be universal for everyone. The answers are very individual, because they explain the differences in the behavior of different people. For example, the answers of the question "Why do some people publish in social networking so much and so often?" could be: narcissism, loneliness, low or high self-esteem, sharing important individual things (joy, pain, events, information, humor etc.) with others. Social media meet quickly, easily and daily important psychological needs of people who have always existed in human and will never disappear. Such needs are for example: the need for to be seenbeing seen is not as important as to see? People post photos, join groups, etc.; the need for affiliation-users are included in the groups, they add friends, follow a popular personality; the need for recognition-users feel better when another users like or commente their publication positively; the human need to be liked-publishing a picture in Facebook is a post could get many likes in minutes. And people definitely understand clearly and emphatically the expressed likes. 
Along with the psychological human needs, the social media's psychology focuses on and also explains the communication in social media. Such communication has an efficient character (achievement of targets with the least resources) because the users have active communication, they are in contact with friends, acquaintances, relatives, colleagues, teachers, strangers, parallel and no matter how far they are; users congratulate their friends for national, religious and personal holidays, they send each other greetings and "Facebook gift", they greet each other with a song or greeting, even they flirt. Also communication in social media creates a proactive public attitude. Facebook has been criticized for alienating people, but it is difficult to agree with this. This network is a platform that brings together people not only online, but also offline. Young people use it mostly to find different forms of real social activities such as concerts, parties, cultural events or romantic dates . Parallel communication in social media creates and pro-social attitudes and develop human altruism. Social media connects people around the world for general humanitarian causes and solidarity such as fighting diseases, renunciation of violence, support for people facing natural disasters, raising money for operations and others and more than million people are involved.

\section{CONCLUSION}

Social media contain many attractive features, but at the same time they are hiding risks that can not remain hidden or ignored. Such risks could be: sharing too intimate sides of human nature and loss of privacy; social media may be a cause for violence, murder and suicide; social media may be a reason for rumors and gossips, also for losing a lot of time and even career; social media may change the perception of reality and may bring the feeling of social isolation or depression; social media may be an occasion for divorces, family conflicts and feelings of loneliness; social media definitely change the habits and may lead to Internet addiction. All these risks can be avoided if users have digital and social competences and if they know how to use rational, responsible, critical and constructive these modern media.

At the same time the digital natives create the digital legacy of their family. Everything they publish like comments, things that engage and demonstrate is stored and forms that digital legacy to the future generations.
It is a time for pedagogical science to focus its sight to this colossal real-life phenomenon, its impact on children, adolescents and adults, and to seek the opportunity to turn it into an educational tool, or at least a tool for support the learning and the education of the students, of the digital natives. There is a sensitive need for fundamental and comprehensive research in macro pedagogical aspects and research the impact of social media on different aged students and young people in Bulgarian conditions and Bulgarian language, not only in English...!

\section{REFERENCES}

1. www.nielsen.com

2. www.slideshare.net/panditvidur/socialnetworking-site-a-new-era-incommunication

3. www.slideshare.net/stevenbelleghem/socialmedia-around-the-world-2011

4. www.socialmediaweek.org

5. http://www.oxforddictionaries.com/definitio n/english/digital-native

6. Berk, Ronald A., Multimedia Teaching with Video Clips: TV, Movies, YouTube, and $\mathrm{mtvU}$ in the College Classroom, International Journal of Technology in Teaching \& Learning. Jun, Vol. 5 Issue 1, p1-21. 21p., 2009.

7. www.slideshare.net/themoleskin/introductio n-to-social-media

8. Kaplan Andreas M., Haenlein Michael. "Users of the world, unite! The challenges and opportunities of social media".Business Horizons 53 (1). p. 61, 2010.

9. Kaplan and Haenlein, Business Horizons (2010) article

10. Shi, Zhan; Rui, Huaxia; Whinston, Andrew B. (forthcoming). "Content Sharing in a Social Broadcasting Environment: Evidence from Twitter". MIS Quarterly.

11. Steel, Emily (September 19). "Myspace Owners Timberlake, Specific Media Shrink Redesign Party". The Wall Street Journal. Retrieved 2011-10-23, 2011.

12. http://vk.com/catalog.php

13. Odnoklassniki Advertising (Russian)

14. The New York Times.Another Try by Google to Take On Facebook. June 28, 2011.

15. D'Monte, Leslie (April 29). "Swine Flu's Tweet Tweet Causes Online Flutter". Business Standard. Retrieved February 4, 2011. "Also known as the 'SMS of the internet', Twitter is a free social 
networking and micro-blogging service", 2009.

16. Eldon, Eric (December 18). "2008 Growth Puts Facebook In Better Position to Make Money". VentureBeat(San Francisco). Retrieved December 19, 2008.

17. The Wall Street Journal(New York). "Facebook Tops Billion-User Mark". October 4, 2012. Retrieved October 4, 2012.
18. Consumer Reports News "Five million Facebook users are 10 or younger".May 10, 2011. Retrieved May 15, 2011.

19. Lantz-Andersson, A ., Vigmo, S ., Bowen, $\mathrm{R}$., international journal of computersupported collaborative learning Volume: 8 Issue:3 Pages: 293312 DOI: 10.1007/s11412-013-91770 Published: SEP 2013

20. Boghian, I. Social media in higher education: teaching in web 2.0, 2013 